\title{
2019 Novel coronavirus (COVID-19) overview
}

\section{Mehrdad Mohammadi ${ }^{1}$ - Maryam Meskini ${ }^{2} \cdot$ Anderia Lucia do Nascimento Pinto $^{3}$}

Received: 4 March 2020 / Accepted: 25 March 2020 / Published online: 19 April 2020

(C) Springer-Verlag GmbH Germany, part of Springer Nature 2020

\begin{abstract}
Novel coronaviruses (CoVs) are zoonotic pathogens, but the first human-to-human transmission has been reported. CoVs have the best known genome of all RNA viruses, and mutations in the genome have now been found. A pneumonia of unknown cause detected in Wuhan, China, was first reported to the WHO Country Office in China on 31 December 2019. This study aims to report early findings related to COVID-19 and provide methods to prevent and treat it.
\end{abstract}

Keywords Coronaviruse $\cdot$ Pathogen $\cdot$ COVID-19

\section{Introduction}

Coronaviruses $(\mathrm{CoVs})$ are non-segmented positive-sense RNA viruses in the Coronaviridae family, Nidovirales order (Woo et al. 2010; Cui et al. 2019). These viruses characteristically contain crown-shaped peplomers of $80-160 \mathrm{nM}$ size with 27-32 kb positive polarity (Woo et al. 2010; Cui et al. 2019). CoVs are pleomorphic and broadly distributed in mammals, especially humans. They have very high recombination rates. Therefore, they are constantly developing transcription errors and RNA-dependent RNA polymerase (RdRP) jumps (Woo et al. 2010; Cui et al. 2019).

CoVs have a high mutation rate (Cui et al. 2019). Zoonotic pathogens (Peiris et al. 2003) are present in humans and various animals and can cause clinical problems in the human respiratory, gastrointestinal, hepatic and neurologic systems with a wide range of asymptomatic strains that lead to hospitalization of patients in intensive care units (ICUs) (Cui et al.

Mehrdad Mohammadi

mehrdad.mohammadi1984@gmail.com

Maryam Meskini

m_meskini@pasteur.ac.ir

Anderia Lucia do Nascimento Pinto

Anderia.lucia.pinto@gmail.com

1 Department of Microbiology, Faculty of Medicine, Kashan University of Medical Sciences, Kashan, Iran

2 Department of Mycobacteriology and Pulmonary Research, Pasteur Institute of Iran, Tehran, Iran

3 National Health Service (NHS), London, UK
2019; Holshue et al. 2020). CoVs used to be considered mild pathogens for humans and are the cause of the common cold (Peiris et al. 2003), but they have gained more attention since being connected with severe acute respiratory syndrome (SARS) in China in 2002 and 2003 with mortality rates of $10 \%$ for SARS-CoV (Ksiazek et al. 2003; Yin and Wunderink 2018). The next of these outbreaks, and its control, occurred approximately 1 decade after SARS-CoV, when another highly pathogenic CoV, Middle East respiratory syndrome coronavirus (MERS-CoV), emerged in Middle Eastern countries such as Saudi Arabia with a $37 \%$ mortality rate (Yin and Wunderink 2018; Zaki et al. 2012; Farooq et al. 2020). Since December 8, 2019, a series of cases of pneumonia of of unknown etiologic origin emerged in Wuhan, Hubei province, China (Zhu et al. 2020). This problem has been the focus of global attention because of clinical presentations, resembling viral epidemic pneumonia of unknown cause (Shen et al. 2020; Chen et al. 2020). Most patients worked at or lived near the local Huanan Seafood Wholesale Market, where livestock animals are traded (Zhu et al. 2020; Shen et al. 2020; Imai et al. 2020).

First, an unknown pneumonia case was detected on December 12, 2019, by laboratory testing, and on January 1, 2020, the seafood market was closed (Zhu et al. 2020). After this, on January 7 , a novel coronavirus was identified by the Chinese Centers for Disease Control and Prevention (CDC) in a throat swab sample of a patient. This report was released by the Wall Street Journal, and the virus was subsequently named 2019-CoV by the World Health Organization (WHO) on January 9 (Tang et al. 2020a). The first viral genome sequence of 2019-nCoV was released online on January 10, one day 
after its formal approval, by Dr. Yong-Zhen Zhang and scientists at Fudan University, Shanghai (Wuhan-Hu-1, GenBank accession no. MN908947) (Wu et al. 2020a). On January 7, 2020, the Chinese higher-ups declared that a new type of coronavirus (novel coronavirus, $\mathrm{nCoV}$ ) had been isolated (Read et al. 2020). This virus changed to COVID-19 on February 11, 2020 (Phan 2020). As of February 12 to March 1, 2020, 87,137 cases of COVID-19 had been reported and 2979 deaths (World Health Organization, 2019-nCoV Situation Report-41 on 01 2020). Although the source of COVID-19 is still unknown, after the first case developed (Phan 2020; Li et al. 2020a), the infection was probably transmitted as a zoonotic agent (from animal to human) (Zhou et al. 2020). The increase in the number of cases in China and internationally has indicated a second transmission from human to human (Phan 2020; Gralinski and Menachery 2020).

The geographic distribution of COVID-19 cases worldwide, as of March 1, 2020, is shown in Fig. 1 (World Health Organization, 2019-nCoV Situation Report-41 on 01 2020). The daily increase in cases of COVID-19 and their distribution by continent (except China) as of March 1, 2020, are shown in Fig. 2 (World Health Organization, 2019-nCoV Situation Report-41 on 01 2020). The number of cases of and deaths from COVID-19 is shown in Table 1 (World Health Organization, 2019-nCoV Situation Report-41 on 01 2020). Given the above statistics, the importance of the issue is clear. This study aimed to describe the methods to prevent and treat COVID-19 and provide an early evaluation of them.

\section{COVID-19 from SARS to MERS}

SARS-CoV, which originated in China and then spread to other parts of the world with hospital-acquired infectious cases, had a mortality rate of $10 \%$ and was transmitted to 8000 people during an 8-month outbreak in 2002-2003 (Ksiazek et al. 2003; Yin and Wunderink 2018; Luk et al. 2019). In 2012, when MERS-CoV emerged in the Arabian Peninsula, it spread to 27 countries with a $35.6 \%$ mortality rate in 2220 cases (Yin and Wunderink 2018; Zaki et al. 2012; Farooq et al. 2020). It is already known that both SARS and MERS are zoonotic viruses showing hospitalacquired and human-to-human transmission (Yin and Wunderink 2018). Similar dynamics apply to this new strain named COVID-19 (CoVs), detected in Wuhan, Hubei Province, China, in December 2019, and the current rate of mortality is about 2\% (Chen et al. 2020; Huang et al. 2020). It is also known that CoVs can use different receptors and pathways when entering the cell (Tortorici et al. 2019).

While SARS-CoV usually infects the youngest (Luk et al. 2019), MERS-CoV targets people aged $>50$ years (Yin and Wunderink 2018), and COVID-19 infects middle-aged groups and above (Phan 2020). Comparing non-respiratory

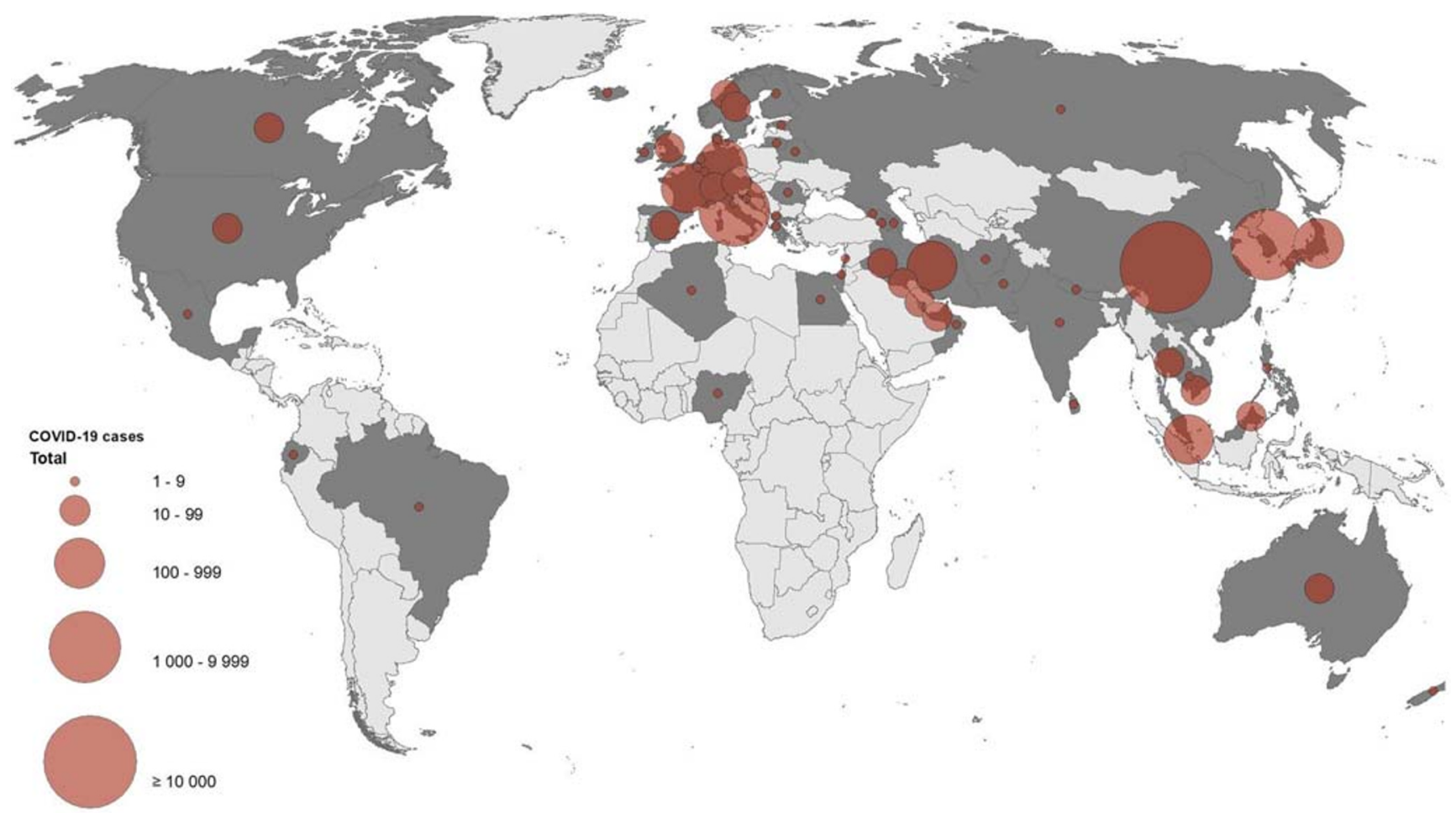

Countries reporting cases

Fig. 1 Geographic distribution of COVID-19 cases worldwide, as of March 1, 2020 


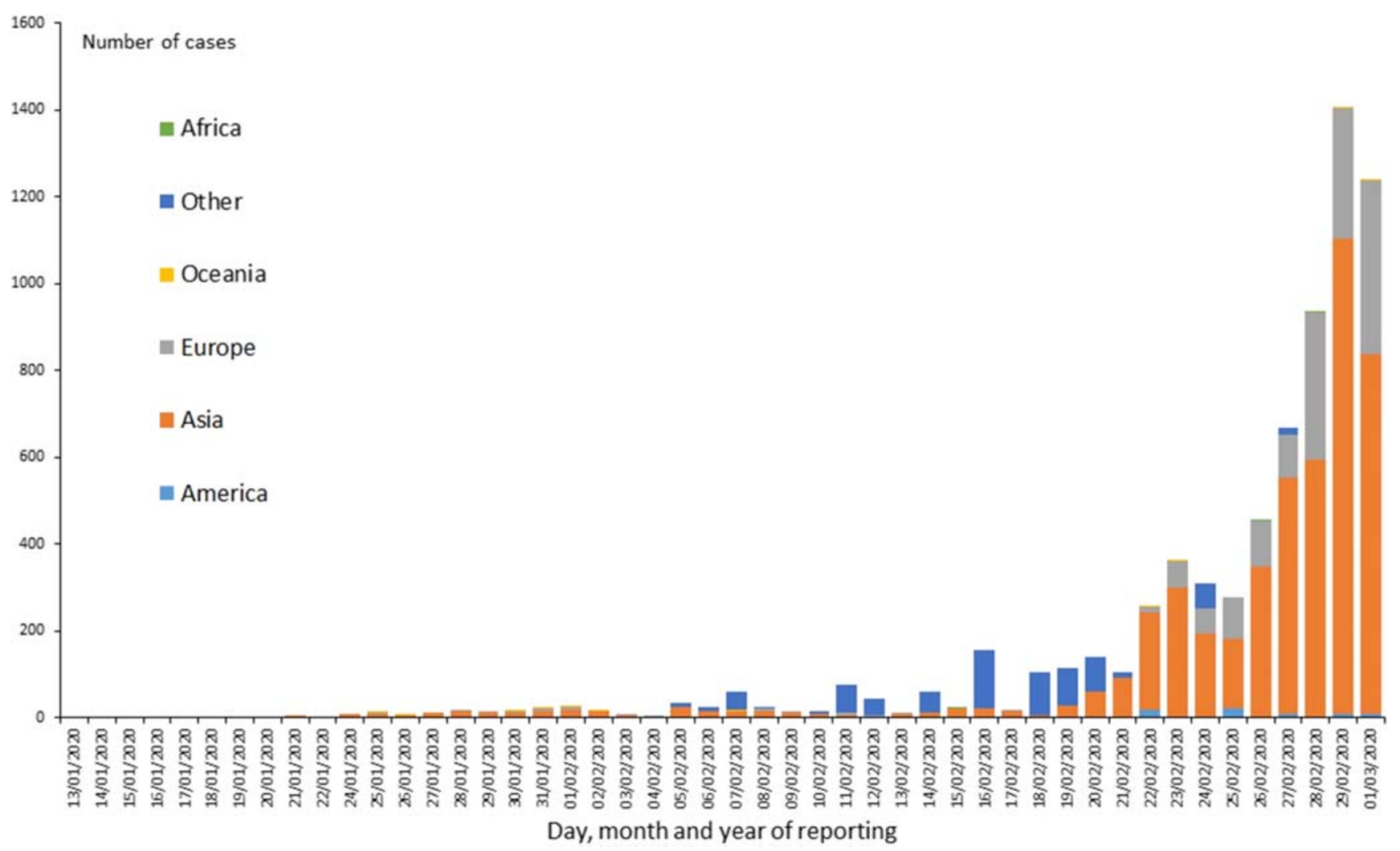

Fig. 2 Distribution of COVID-19 cases by continent (except China), as of March 1, 2020

complications, MERS-CoV involves the cardiovascular system more frequently than SARS-CoV and frequently requires vasopressor treatment (Cui et al. 2019; Yin and Wunderink 2018). On the other hand, some case reports have shown that COVID-19 affects the cardiovascular system (Lu et al. 2020; Cao et al. 2020). Acute kidney failure was more frequently observed in SARS-CoV and MERS-CoV epidemics compared with COVID-19 cases (Farooq et al. 2020; Luk et al. 2019). Whereas radiologic findings are present in all three pathogens, airspace opacifications are seen in SARS-CoV and a groundglass appearance in MERS-CoV and COVID-19 (Yin and Wunderink 2018; Jin et al. 2020).

Hospital-acquired secondary infections have been described for all three pathogens (Cui et al. 2019). Despite the knowledge about its etiology, no studies have reported a successful drug to treat the diagnosed patients (Wu et al. 2020b; Nguyen et al. 2020). Regarding the epidemic periods, SARS$\mathrm{CoV}$ has had the shortest reported epidemic period so far, ending less than a year after its outbreak (Luk et al. 2019), and the MERS-CoV epidemic lasted for 7 years even though its spread was toward a more restricted area (Farooq et al. 2020). The questions that follow are how long this novel COVID-19 strain outburst will last and what its impact on the world population will be, questions everyone is curious about.

\section{Virus genome and structure}

CoVs are the best-known genome structure among all RNA viruses (Woo et al. 2010). Two-thirds of their RNA has viral polymerase (RdRp), RNA synthesis materials and two large non-structural polyproteins that are not involved in host response modulation (ORF1a-ORF1b) (Jordan et al. 2018). One-third of the genome encodes four structural proteins, spike (S), envelope (E), membrane (M) and nucleocapsid $(\mathrm{N})$, as well as other helper proteins (Lu et al. 2020; Paraskevis et al. 2020). Even though the length of the CoV genome showed high variability for ORF1a/ORF1b and four structural proteins (Jordan et al. 2018; Paraskevis et al. 2020), it is mostly associated with the number and size of accessory proteins (Cui et al. 2019; Tortorici et al. 2019). The first step in virus infection was the interaction of sensitive human cells with S protein (Tortorici et al. 2019; Cao et al. 2020). Genome encoding occurs after entering the cell and facilitates the expression of the genes (Cui et al. 2019), which encode useful accessory proteins (Tortorici et al. 2019), and these advance the adaptation of $\mathrm{CoVs}$ to their human host $(\mathrm{Lu}$ et al. 2020). Genome changes resulting from recombination, gene exchange, gene insertion or deletion have been frequent among CoVs, and this will take place in future outbreaks as well (Paraskevis et al. 2020). The CoV subfamily is rapidly expanding with new generation sequencing applications that 
Table 1 The number of cases of and deaths from the COVID-19 outbreak according to World Health Organization (WHO) Situation Report-41 on March 1, 2020 (Woo et al. 2010)

\begin{tabular}{|c|c|c|c|c|}
\hline Regions & Places reporting cases & Confirmed cases & Deaths & Comments \\
\hline Asia & China & 79,968 & 2873 & Including 66,907 cases from Hubei Povince \\
\hline Asia & Republic of Korea & 3600 & 18 & \\
\hline Asia & Iran & 593 & 43 & \\
\hline Asia & Japan & 239 & 5 & \\
\hline Asia & Singapore & 102 & 0 & \\
\hline Asia & Kuwait & 45 & 0 & \\
\hline Asia & Thailand & 42 & 0 & \\
\hline Asia & Bahrain & 41 & 0 & \\
\hline Asia & Taiwan & 40 & 0 & \\
\hline Asia & Malaysia & 25 & 0 & \\
\hline Asia & United Arab Emirates & 21 & 0 & \\
\hline Asia & Vietnam & 16 & 0 & \\
\hline Asia & Iraq & 13 & 0 & \\
\hline Asia & Israel & 7 & 0 & \\
\hline Asia & Oman & 6 & 0 & \\
\hline Asia & Lebanon & 4 & 0 & \\
\hline Asia & Pakistan & 4 & 0 & \\
\hline Asia & India & 3 & 0 & \\
\hline Asia & Philippines & 3 & 1 & \\
\hline Asia & Sri Lanka & 1 & 0 & \\
\hline Asia & Afghanistan & 1 & 0 & \\
\hline Asia & Qatar & 1 & 0 & \\
\hline Asia & Nepal & 1 & 0 & \\
\hline Asia & Cambodia & 1 & 0 & \\
\hline Europe & Italy & 1128 & 29 & \\
\hline Europe & Germany & 111 & 0 & \\
\hline Europe & France & 100 & 2 & \\
\hline Europe & Spain & 66 & 0 & \\
\hline Europe & UK & 23 & 0 & \\
\hline Europe & Switzerland & 18 & 0 & \\
\hline Europe & Norway & 15 & 0 & \\
\hline Europe & Sweden & 13 & 0 & \\
\hline Europe & Austria & 10 & 0 & \\
\hline Europe & Greece & 7 & 0 & \\
\hline Europe & The Netherlands & 7 & 0 & \\
\hline Europe & Croatia & 5 & 0 & \\
\hline Europe & Finland & 3 & 0 & \\
\hline Europe & Georgia & 3 & 0 & \\
\hline Europe & Denmark & 3 & 0 & \\
\hline Europe & Romania & 3 & 0 & \\
\hline Europe & Russia & 2 & 0 & \\
\hline Europe & Monaco & 1 & 0 & \\
\hline Europe & Azerbaijan & 1 & 0 & \\
\hline Europe & North Macedonia & 1 & 0 & \\
\hline Europe & Ireland & 1 & 0 & \\
\hline Europe & Estonia & 1 & 0 & \\
\hline Europe & Iceland & 1 & 0 & \\
\hline Europe & Lithuania & 1 & 0 & \\
\hline
\end{tabular}


Table 1 (continued)

\begin{tabular}{|c|c|c|c|c|}
\hline Regions & Places reporting cases & Confirmed cases & Deaths & Comments \\
\hline Europe & Armenia & 1 & 0 & \\
\hline Europe & Belarus & 1 & 0 & \\
\hline Europe & Luxembourg & 1 & 0 & \\
\hline Europe & Belgium & 1 & 0 & \\
\hline Europe & San Marino & 1 & 0 & \\
\hline Other & Cases on an international conveyance, Japan & 705 & 6 & \\
\hline America & USA & 69 & 1 & \\
\hline America & Canada & 20 & 0 & \\
\hline America & Mexico & 4 & 0 & \\
\hline America & Brazil & 2 & 0 & \\
\hline America & Ecuador & 1 & 0 & \\
\hline Oceania & Australia & 26 & 1 & \\
\hline Oceania & New Zealand & 1 & 0 & \\
\hline Africa & Egypt & 1 & 0 & \\
\hline Africa & Nigeria & 1 & 0 & \\
\hline \multirow[t]{2}{*}{ Africa } & Algeria & 1 & 0 & \\
\hline & Total & 87,137 & 2979 & \\
\hline
\end{tabular}

improve the detection and definition of novel $\mathrm{CoV}$ species (Read et al. 2020). Briefly, CoV classification is continually changing. According to the most recent ranking of the International Committee on the Taxonomy of Viruses (ICTV), there are 4 genera of 38 unique species (Cui et al. 2019).

\section{Pathogenesis}

SARS-CoV and MERS-CoV attach to the host cell respectively bind to cellular receptor angiotensin-converting enzyme 2 (SARS-CoV associated) and cellular receptor of dipeptidyl peptidase 4 (MERS-CoV associated) (Tortorici et al. 2019; Park et al. 2019; Letko et al. 2020). The viral RNA replicates in the cytoplasm after entering the cell (Letko et al. 2020). Genomic RNA is encapsulated and polyadenylated, and it encodes various structural and non-structural polypeptide genes (Cui et al. 2019; Subissi et al. 2014). These polyproteins are split by proteases that exhibit chymotrypsin-like activity (Subissi et al. 2014; Goo et al. 2020). The resulting complex drives (-) RNA production through both replication and transcription (Jordan et al. 2018). During replication, full-length $(-)$ RNA copies of the genome are produced and used as a template for full-length (+) RNA genomes (Cui et al. 2019; Jordan et al. 2018). During transcription, a subset of 7-9 subgenomic RNAs, including those encoding all structural proteins, are produced by discontinuous transcription (Cui et al. 2019; Jordan et al. 2018). Viral nucleocapsids are combined from genomic RNA and R protein in the cytoplasm and then are budded into the lumen of the endoplasmic reticulum (Cui et al. 2019). Virions are then released from the infected cell through exocytosis (Cui et al. 2019). The released viruses can infect kidney cells, liver cells, the intestines and T lymphocytes, as well as the lower respiratory tract, where they cause the main symptoms and signs. Remarkably, CDT lymphocytes were found to be $<200$ cells $/ \mathrm{mm} 3$ in three patients with SARS-CoV infection (Cui et al. 2019; Luk et al. 2019; Paraskevis et al. 2020). MERS-CoV can affect human dendritic cells, macrophages and $\mathrm{T}$ lymphocytes. This virus can make the antiviral $\mathrm{T}$ cell response irregular because of the stimulation of $\mathrm{T}$ cell apoptosis, thus causing a collapse of the immune system (Farooq et al. 2020; Park et al. 2019; Goo et al. 2020; Cockrell et al. 2016).

\section{Epidemiology}

In December 2019, many pneumonia cases clustered in Wuhan were reported, and a search determined the source to be the Huanan seafood market (Chan et al. 2020). The first patient of the COVID-19 epidemic was discovered with unexplained pneumonia on December 12, 2019, and 27 viral pneumonia cases, 7 severe, were officially made known on December 31, 2019 (Zhu et al. 2020; Tang et al. 2020a). Etiologic investigations were made into patients who applied to the hospital for similar viral pneumonia findings (Chen et al. 2020). The natural history of high-risk animal contact in the medical histories of these patients has strengthened the likelihood of an infection transmitted from animals to humans 
(Wu et al. 2020a; Zhou et al. 2020). On January 22, 2020, novel CoVs were confirmed to originate from wild bats and belong to Group 2 of the beta-coronaviruses, which includes severe acute respiratory syndrome associated coronavirus (SARS-CoV) (Paraskevis et al. 2020). Although COVID-19 and SARS-CoV belonged to the same beta coronavirus subgroup, genome-level similarities were only $70 \%$, because the novel group has been found to show genetic differences from SARS-CoV (Lu et al. 2020; Paraskevis et al. 2020). The outbreak of the SARS epidemic and COVID-19 occurred during the Spring Festival in China (SFC), the country's most famous traditional festival, during which nearly 3 billion people travel countrywide (Chen et al. 2020; Li et al. 2020a). These situations caused ideal conditions for the transmission of this highly contagious disease and severe difficulties in prevention and control of the epidemic (Read et al. 2020). The SFC lasted from January 17 to February 23 in 2003, when the SARS epidemic peaked, and in 2020 January 10 to February 18 was the time of the SFC (Peiris et al. 2003). Similarly, there was a quick increase in COVID-19 cases between January 1022 (Read et al. 2020).

\section{Transmission}

CoVs have been defined as a novel respiratory tract virus in the samples collected from individuals who presented symptoms of respiratory tract infection in 1962 (Cui et al. 2019). $\mathrm{CoVs}$ are a large family of viruses that are common in many different animal species, including camels, cattle, cats and bats (Cui et al. 2019). Rarely, animal CoVs can infect humans and, as a result, may spread among humans during epidemics such as MERS, SARS and COVID-19 (Wu et al. 2020a). At the onset of significant outbreaks caused by CoVs, palm civets have been proposed to be a natural reservoir of human CoVs for SARS and dromedary camels for MERS (Cui et al. 2019; Yin and Wunderink 2018).

Conversely, more advanced virologic and genetic studies have shown that bats are reservoir hosts of both SARS-CoV and MERS-CoV (Yin and Wunderink 2018), and before these viruses spread to humans (Cui et al. 2019), they use the other animals as intermediate hosts. Studies have reported that most of the bat CoVs are the gene source of alpha-CoVs and beta$\mathrm{CoVs}$, whereas most of the bird CoVs are the gene source of gamma-CoVs and delta-CoVs (Zhou et al. 2020). Recent studies have shown that the novel virus causing epidemics coincides with the $\mathrm{CoV}$ isolated in bats (Wu et al. 2020a; Zhou et al. 2020; Drexler et al. 2010). The presence of the wild animal trade in the Huanan seafood market, where the first cases appeared, supports this finding (Wu et al. 2020a; Zhou et al. 2020).

After the first outbreak, secondary cases began to be reported after approximately 10 days (Wu et al. 2020c). Moreover, while these new patients had no contact with the marketplace, they had a history of contact with humans there (Wu et al. 2020c). Confirmed recent reports from many infected healthcare workers in Wuhan show that human-to-human transmission can occur (Chan et al. 2020). As in SARS and MERS epidemics in the past, human-to-human transmission has accelerated the spread of the outbreak, and case reports have also started from other provinces in China (Luk et al. 2019). The first non-Chinese case of the infection, which spread to the Chinese provinces, and then to the Asian continent, was reported from Thailand on January 13, 2020 (World Health Organization, 2019-nCoV Situation Report-41 on 01 2020). The patient reported being a Chinese tourist who had traveled to Thailand and had no epidemiologic connection with the marketplace ( $\mathrm{Li}$ et al. 2020a). Other evidence from overseas countries such as the USA (Holshue et al. 2020) and France has continued to be reported (Stoecklin et al. 2020). This virus disseminated to the Midle Eastern region; for example, Iran was a region with potential to develop a major epidemiologic problem for healthcare (Zamani Ghaleshahi et al. 2020; Tuite et al. 2020). This virus has the potential to become a pandemic problem (MacIntyre 2020).

Frequently, close contact leads to human-to-human transmission (Chan et al. 2020). The transmission primarily occurs when an infected person sneezes and through the respiratory droplets produced, like in the spread of influenza and other respiratory pathogens (Chen et al. 2020; Read et al. 2020). These droplets can settle in the mouth or nasal mucosa and lungs of people with inhaled air ( $\mathrm{Li}$ et al. 2020a). Currently, it remains unclear whether COVID-19 can infect a person by touching an infected surface or object and then touching their mouth, nose or possibly eyes (Chen et al. 2020; Phan 2020).

Typically, like most respiratory viruses, it is considered to be the most contagious when people are most symptomatic (Phan 2020). However, patients who were infected by an asymptomatic person in the prodromal period of COVID-19 have also been reported (Jin et al. 2020). Sufficient data are not available on the infectiousness of the disease, and research is ongoing.

\section{Diagnosis}

Before the cases of SARS-CoV, it was thought that human CoVs lead to a cold-like upper respiratory infection and selflimiting lower respiratory infection (Yin and Wunderink 2018). The first death due to coronaviruses was reported by the isolation of SARS-CoV from a patient with pneumonia in China (Ksiazek et al. 2003). As in other respiratory infection viruses and previous beta-CoVs, there are similarities in the clinical aspects of COVID-19 infections, and it is known that the clinical picture varies from simple respiratory infections to septic shock (Gralinski and Menachery 2020). Similar to 
SARS-CoV and MERS-CoV, which have caused epidemics in the past years (Yin and Wunderink 2018), the first symptoms are commonly fever, cough and shortness of breath (Huang et al. 2020). Although diarrhea was present in about 20-25\% of patients with MERS-CoV or SARS-CoV infection (Yin and Wunderink 2018), intestinal symptoms have rarely been reported in patients with COVID-19 (Huang et al. 2020). In another study, which included 99 patients, chest pain, confusion and nausea-vomiting were noted in addition to previous findings (Chen et al. 2020). On x-rays or thorax CT imaging of the examined patients, unilateral or bilateral involvement compatible with viral pneumonia was found, and bilateral multiple lobular and sub-segmental consolidation areas were observed in patients hospitalized in the intensive care unit (Chen et al. 2020; Huang et al. 2020; Tang et al. 2020b).

In a cohort study that surveyed 41 hospitalized patients, fever, dry cough, myalgia and fatigue symptoms were reported in most patients; less often, symptoms of expectoration, headache, hemoptysis and diarrhea were also observed (Huang et al. 2020). According to the study, comorbidities such as underlying diabetes mellitus, hypertension and cardiovascular disease were found in about half of these patients (Huang et al. 2020). In addition, patients developed dyspnea accompanied by abnormal thorax CT compatible with pneumonia at mean 8 days after admission (Chen et al. 2020). Complications include ARDS, acute heart damage, secondary infections and pneumothorax. Similar to the previous data, $\mathrm{x}$ rays or thorax $\mathrm{CT}$ images of the patients revealed unilateral or bilateral lung involvement, compatible with viral pneumonia. Bilateral multiple lobular and sub-segmental consolidation areas were present in patients in the intensive care unit (Chen et al. 2020; Gralinski and Menachery 2020; Huang et al. 2020; Jin et al. 2020). The patients with underlying comorbidity exhibited a more severe clinical course, as expected from the experience gained from the previous epidemics (Jin et al. 2020).

As in SARS and MERS, the diagnosis of 2019n-CoV infection is based on a history of detailed contact and travel and precise laboratory testing (Jin et al. 2020). The diagnostic tools are molecular methods, serology and viral culture (Gralinski and Menachery 2020; Jin et al. 2020; Corman et al. 2020). The most common diagnostic methods are molecular methods such as reverse transcription-polymerase chain reaction (RT-PCR) or real-time PCR, which are made using RNA from respiratory samples such as oropharyngeal swabs, sputum, nasopharyngeal aspirates, deep tracheal aspirates or broncho-alveolar lavage (Corman et al. 2020). In particular, lower respiratory tract samples can offer a significantly higher viral load and genome fraction than upper respiratory tract samples. These techniques are beneficial in terms of evaluating the results quickly, showing the genome structure and viral load (Corman et al. 2020).
The sensitivity of antibody detection is generally lower than that of molecular methods and is mostly used in retrospective diagnosis (Goo et al. 2020; Li et al. 2020b). Viral culture is a more time-consuming method compared with the other methods. Culture is much more useful in the first stage of outbreaks before other diagnostic methods become clinically available. In addition, viral cultures can be used in the invitro and in-vivo antiviral treatment and vaccine evaluation trials (Jin et al. 2020; Li et al. 2020b).

\section{Prevention and treatment}

In general, there are few or no treatment options for viral diseases of sudden occurrence (Nguyen et al. 2020). Today, there is no vaccine or effective treatment to prevent COVID19 infection (Nguyen et al. 2020). Molecules are being tested for COVID-19 in in-vitro and human-based SARS-CoV, and MERS-Cov trials, and studies evaluating the antiviral activity of types I and II interferons have reported interferon-beta (IFNb) as the most potent interferon, which reduced in-vitro MERS-CoV replication (Nguyen et al. 2020; Arabi et al. 2018). According to a human MERS-CoV case report from South Korea, use of the combination of lopinavir/ritonavir (LPV/RTV) (anti-HIV drugs), pegylated interferon and ribavirin provided successful viral clearance (Arabi et al. 2018). Another antiviral drug, remdesivir, was used in the first case reported in the USA, and it seemed successful; however, more cases are needed (Wang et al. 2020). In-vitro studies have shown that viral RNA transcription was terminated with remdesivir in the early stages. Remdesivir showed strong antiviral activity in epithelial cell cultures against SARS-CoV, MERS-CoV and related zoonotic bat CoVs (Wu et al. 2020b; Wang et al. 2020; Brown et al. 2019).

In this early stage, dissemination of information is key, such as timely publication of epidemic statistics, early diagnosis, reporting, isolation and treatment. The CDC emphasizes necessary measures such as hand washing using disinfectant solutions and having minimal contact with patients to prevent the spread of the viral particles. Precautionary measures, including the provision of medicine supply chains, personal protection equipment and hospital supplies, should be carried out immediately not only for the protection of the Chinese people but also for the consequences for global health, especially in the places with travel ports close to major Chinese ports (Jin et al. 2020).

Based on the 2003 SARS-CoV epidemic, the Chinese government carried out many effective measures, including limited access to public transportation, reducing migration flow and promoting personal protection providing masks to the inhabitants of Wuhan and other provinces. However, there are already reported cases of infected hospital personnel. Therefore, healthcare staff should be informed about and 
compelled to comply with any protective measures necessary, such as the use of gloves, eye masks and N95 masks when examining patients who could have been in contact with infected patients or have traveled to or been close to areas reporting cases of infection (China) (Phan 2020; Li et al. 2020a; Jin et al. 2020).

\section{Future extension of COVID-19}

We need to consider the future course of COVID-19, which, as of February 12, 2020, had spread to 64 countries with 87,137 confirmed cases and 2979 deaths (Table 1). With globalization, coronaviruses will spread, and there will be similar outbreaks of different mutant strains in the coming years. With increased international scientific collaboration, we may develop more powerful means of fighting coronaviruses, and we may understand the genome structure very well in the future. We have to be conscious of the challenges and worries 2019$\mathrm{nCoV}$ has brought to our communities worldwide. Strenuous efforts should be made to learn about about and control the disease, and the time to act is now.

\section{Compliance with ethical standards}

\section{Consent for publication Not applicable.}

Competing interests The authors declare that they have no competing interests.

\section{References}

Arabi YM, Alothman A, Balkhy HH, Al-Dawood A, AlJohani S, Al Harbi S et al (2018) Treatment of Middle East respiratory syndrome with a combination of lopinavir-ritonavir and interferon- $\beta 1 \mathrm{~b}$ (MIRACLE trial): study protocol for a randomized controlled trial. Trials. 19(1):81

Brown AJ, Won JJ, Graham RL, Dinnon KH III, Sims AC, Feng JY et al (2019) Broad spectrum antiviral remdesivir inhibits human endemic and zoonotic deltacoronaviruses with a highly divergent RNA dependent RNA polymerase. Antivir Res 169:104541

Cao Y, Li L, Feng Z, Wan S, Huang P, Sun X et al (2020) Comparative genetic analysis of the novel coronavirus (2019-nCoV/SARS-CoV2) receptor ACE2 in different populations. Cell Discovery 6(1):1-4

Chan JF-W, Yuan S, Kok K-H, To KK-W, Chu H, Yang J et al (2020) A familial cluster of pneumonia associated with the 2019 novel coronavirus indicating person-to-person transmission: a study of a family cluster. Lancet 395(10223):514-523

Chen N, Zhou M, Dong X, Qu J, Gong F, Han Y et al (2020) Epidemiological and clinical characteristics of 99 cases of 2019 novel coronavirus pneumonia in Wuhan, China: a descriptive study. Lancet 395(10223):507-513

Cockrell AS, Yount BL, Scobey T, Jensen K, Douglas M, Beall A et al (2016) A mouse model for MERS coronavirus-induced acute respiratory distress syndrome. Nat Microbiol 2(2):1-11
Corman VM, Landt O, Kaiser M, Molenkamp R, Meijer A, Chu DK et al (2020) Detection of 2019 novel coronavirus (2019-nCoV) by realtime RT-PCR. Eurosurveillance 25(3):2000045

Cui J, Li F, Shi Z-L (2019) Origin and evolution of pathogenic coronaviruses. Nat Rev Microbiol 17(3):181-192

Drexler JF, Gloza-Rausch F, Glende J, Corman VM, Muth D, Goettsche $\mathrm{M}$ et al (2010) Genomic characterization of severe acute respiratory syndrome-related coronavirus in European bats and classification of coronaviruses based on partial RNA-dependent RNA polymerase gene sequences. J Virol 84(21):11336-11349

Farooq HZ, Davies E, Ahmad S, Machin N, Hesketh L, Guiver M et al (2020) Middle East respiratory syndrome coronavirus (MERS$\mathrm{CoV}$ ) - surveillance and testing in North England from 2012 to 2019. Int J Infect Dis 93:237-244

Goo J, Jeong Y, Park Y-S, Yang E, Jung D-I, Rho S et al (2020) Characterization of novel monoclonal antibodies against MERS-coronavirus spike protein. Virus Res 278:197863

Gralinski LE, Menachery VD (2020) Return of the coronavirus: 2019nCoV. Viruses. 12(2):135

Holshue ML, DeBolt C, Lindquist S, Lofy KH, Wiesman J, Bruce H et al (2020) First case of 2019 novel coronavirus in the United States. N Engl J Med 382(10):929-936

Huang C, Wang Y, Li X, Ren L, Zhao J, Hu Y et al (2020) Clinical features of patients infected with 2019 novel coronavirus in Wuhan, China. Lancet 395(10223):497-506

Imai N, Dorigatti I, Cori A, Donnelly C, Riley S, Ferguson NM (2020) Report 2: Estimating the potential total number of novel Coronavirus cases in Wuhan City, China. Imperial College London, 22 Jan 2020

Jin Y-H, Cai L, Cheng Z-S, Cheng H, Deng T, Fan Y-P et al (2020) A rapid advice guideline for the diagnosis and treatment of 2019 novel coronavirus (2019-nCoV) infected pneumonia (standard version). Military Medical Research 7(1):4

Jordan PC, Liu C, Raynaud P, Lo MK, Spiropoulou CF, Symons JA et al (2018) Initiation, extension, and termination of RNA synthesis by a paramyxovirus polymerase. PLoS Pathog 14(2):e1006889

Ksiazek TG, Erdman D, Goldsmith CS, Zaki SR, Peret T, Emery S et al (2003) A novel coronavirus associated with severe acute respiratory syndrome. N Engl J Med 348(20):1953-1966

Letko M, Marzi A, Munster V (2020) Functional assessment of cell entry and receptor usage for SARS-CoV-2 and other lineage B betacoronaviruses. Nat Microbiol 5(4):562-569

Li J-Y, You Z, Wang Q, Zhou Z-J, Qiu Y, Luo R et al (2020a) The epidemic of 2019-novel-coronavirus (2019-nCoV) pneumonia and insights for emerging infectious diseases in the future. Microbes Infect 22(2):80-85

Li M, Jin R, Peng Y, Wang C, Ren W, Lv F et al (2020b) Generation of antibodies against COVID-19 virus for development of diagnostic tools. medRxiv. https://doi.org/10.1101/2020.02.20.20025999

Lu R, Zhao X, Li J, Niu P, Yang B, Wu H et al (2020) Genomic characterisation and epidemiology of 2019 novel coronavirus: implications for virus origins and receptor binding. Lancet 395(10224):565-574

Luk HK, Li X, Fung J, Lau SK, Woo PC. Molecular epidemiology, evolution and phylogeny of SARS coronavirus. Infection, Genetics and Evolution. 2019

MacIntyre CR (2020) Global spread of COVID-19 and pandemic potential. Global Biosecurity. https://doi.org/10.31646/gbio.55

Nguyen TM, Zhang Y, Pandolfi PP (2020) Virus against virus: a potential treatment for 2019-nCov (SARS-CoV-2) and other RNA viruses. Cell Res 30(3):189-190

Paraskevis D, Kostaki EG, Magiorkinis G, Panayiotakopoulos G, Sourvinos G, Tsiodras S (2020) Full-genome evolutionary analysis of the novel corona virus (2019-nCoV) rejects the hypothesis of emergence as a result of a recent recombination event. Infect Genet Evol 79:104212 
Park Y-J, Walls AC, Wang Z, Sauer MM, Li W, Tortorici MA et al (2019) Structures of MERS-CoV spike glycoprotein in complex with sialoside attachment receptors. Nat Struct Mol Biol 26(12):11511157

Peiris J, Lai S, Poon L, Guan Y, Yam L, Lim W et al (2003) Coronavirus as a possible cause of severe acute respiratory syndrome. Lancet 361(9366):1319-1325

Phan T (2020) Genetic diversity and evolution of SARS-CoV-2. Infect Genet Evol 81:104260

Read JM, Bridgen JR, Cummings DA, Ho A, Jewell CP. Novel coronavirus 2019-nCoV: early estimation of epidemiological parameters and epidemic predictions. medRxiv. 2020

Shen M, Peng Z, Xiao Y, Zhang L (2020) Modelling the epidemic trend of the 2019 novel coronavirus outbreak in China. bioRxiv. https:// doi.org/10.1101/2020.01.23.916726

Stoecklin SB, Rolland P, Silue Y, Mailles A, Campese C, Simondon A et al (2020) First cases of coronavirus disease 2019 (COVID-19) in France: surveillance, investigations and control measures, January 2020. Eurosurveillance. 25(6):2000094

Subissi L, Posthuma CC, Collet A, Zevenhoven-Dobbe JC, Gorbalenya AE, Decroly E et al (2014) One severe acute respiratory syndrome coronavirus protein complex integrates processive RNA polymerase and exonuclease activities. Proc Natl Acad Sci 111(37):E3900 E39E9

Tang JW, Tambyah PA, Hui DSC (2020a) Emergence of a novel coronavirus causing respiratory illness from Wuhan, China. J Infect 80(3): $350-371$

Tang B, Wang X, Li Q, Bragazzi NL, Tang S, Xiao Y et al (2020b) Estimation of the transmission risk of the 2019-nCoV and its implication for public health interventions. J Clin Med 9(2):462

Tortorici MA, Walls AC, Lang Y, Wang C, Li Z, Koerhuis D et al (2019) Structural basis for human coronavirus attachment to sialic acid receptors. Nat Struct Mol Biol 26(6):481-489

Tuite AR, Bogoch I, Sherbo R, Watts A, Fisman DN, Khan K (2020) Estimation of COVID-2019 burden and potential for international dissemination of infection from Iran. medRxiv. https://doi.org/10. $1101 / 2020.02 .24 .20027375$
Wang M, Cao R, Zhang L, Yang X, Liu J, Xu M et al (2020) Remdesivir and chloroquine effectively inhibit the recently emerged novel coronavirus (2019-nCoV) in vitro. Cell Res 30(3):269-271

Woo PC, Huang Y, Lau SK, Yuen K-Y (2010) Coronavirus genomics and bioinformatics analysis. viruses 2(8):1804-1820

World Health Organization, 2019-nCoV Situation Report-41 on 012020. https://www.who.int/docs/defaultsource/coronaviruse/situationreports/

Wu F, Zhao S, Yu B, Chen Y-M, Wang W (2020a) Song Z-G, et al. A new coronavirus associated with human respiratory disease in China, Nature

Wu C, Liu Y, Yang Y, Zhang P, Zhong W, Wang Y et al (2020b) Analysis of therapeutic targets for SARS-CoV-2 and discovery of potential drugs by computational methods. Acta Pharm Sin B. https://doi.org/ 10.1016/j.apsb.2020.02.008

Wu JT, Leung K, Leung GM (2020c) Nowcasting and forecasting the potential domestic and international spread of the 2019-nCoV outbreak originating in Wuhan, China: a modelling study. Lancet 395(10225):689-697

Yin Y, Wunderink RG (2018) MERS, SARS and other coronaviruses as causes of pneumonia. Respirology. 23(2):130-137

Zaki AM, Van Boheemen S, Bestebroer TM, Osterhaus AD, Fouchier RA (2012) Isolation of a novel coronavirus from a man with pneumonia in Saudi Arabia. N Engl J Med 367(19):1814-1820

Zamani Ghaleshahi A, Ezzatpanah H, Rajabzadeh G, Ghavami M (2020) Comparison and analysis characteristics of flax, perilla and basil seed oils cultivated in Iran. J Food Sci Technol 57(4):1258-1268

Zhou P, Yang X-L, Wang X-G, Hu B, Zhang L, Zhang W et al (2020) A pneumonia outbreak associated with a new coronavirus of probable bat origin. Nature 579(7798):270-273

Zhu N, Zhang D, Wang W, Li X, Yang B, Song J et al (2020) A novel coronavirus from patients with pneumonia in China, 2019. N Engl $\mathrm{J}$ Med 382(8):727-733

Publisher's note Springer Nature remains neutral with regard to jurisdictional claims in published maps and institutional affiliations. 